\title{
EL ECO DE LA BATALLA DE ALMANSA EN LA PUBLICÍSTICA
}

\author{
ROSA Ma ALABRÚS \\ UNED-Barcelona
}

Empezaré por decir que sorprende el escaso eco que la batalla de Almansa tuvo en la publicística de 1707 , lo que contrasta con el abundante espacio que le dedican las grandes crónicas de la guerra (Vicente Bacallar, Agustín López de Mendoza y Pons, Nicolás Belando, Frances de Castellví), todas ellas escritas habiendo ya pasado no pocos años desde la batalla de Almansa.

A la hora de estudiar la publicística hay que delimitar los dos grandes discursos ideológicos: el borbónico y el austracista ${ }^{\text {I }}$.

\section{EL DISCURSO BORBÓNICO}

Es curioso constatar cómo en la publicística borbónica no se encuentran descripciones de la batalla de Almansa. Dominó la glosa sobre la narración de los hechos y de manera inmediata la batalla no tuvo la transcendente significación que después se le pudo atribuir en el desarrollo de la guerra. De hecho, a Berwick no se le concedió la grandeza de España hasta octubre de 1707, seis meses después de su victoria. Los folletos del momento aluden a la «gran victoria» de Almansa y al hecho de que Felipe $\mathrm{V}$ mandase construir, para eternizarlo, una columna de piedra «para mantener la memoria viva con los años» ${ }^{2}$. La Relación que al rey Nuestro $S$ r. haze un coronel de sus Ejércitos de los felizes sucesos y completa victoria resalta la bondad y la generosidad de Felipe $\mathrm{V}$ y glosa al francés Asfeld ante la opinión pública:

1. M. T. PÉrez PICAZo. La publicística española en la guerra de Sucesión, Madrid, 1949, vols I y II; R. $\mathrm{M}^{\mathrm{a}}$ ALABrús, Pensament politic i opinió a la Catalunya Moderna (1652-1759), tesis doctoral, UAB, Barcelona, 1995; R. Ma ALABRús. FelipV i l'opinió dels catalans, Lleida, 2001

2. BC (Biblioteca de Catalunya). Ave Maria. Extollens Vocem Quaedam. Folleto Bonsoms, $\mathrm{n}^{\circ} 8128$, año 1707. 
«Pero el noble cavallero / Dansfeld, con cordura y maña / con su gente valerosa / fuertemente los ataca. / Pasaron toda la noche / y la siguiente mañana/pidieron los enemigos / pacto de bandera blanca. / Reservóseles las vidas / con condición, que quedaran / por prisioneros de guerra / rendidos a nuestras armas / diose con lauros y triunfos $\rangle^{3}$.

Algunos folletos se refieren a la actuación del ejército victorioso después de la batalla de Almansa: «Atacaron a sus enemigos con tan intrépido brío que siguiéndoles en su precipitada fuga hasta tres leguas del campo, lo dejaron poblado de funestos y horrorosos escarmientos». Pero sobre todo se manifestó un interés en cuantificar el número de víctimas austracistas «pasando de seis mil los que dejaron muertos, y de diez mil prisioneros, sin que de los demás salvasen sus vidas más que aquellos, que en tan gran derrota tuvieron mejores cavallos ${ }^{4}$.

En otros folletos las cifras que se barajan son cinco mil muertos y nueve mil prisioneros alegando que Almansa había quedado como un:

«Campo de cadaveres cubierto / pues de cinco mil pasaban / a quienes dieron entierro / sin redoble de campanas / porque no hizieron porque / tengan sufragios sus almas / y mas la que Gallovay / aquel herege, mandaba / y los heridos segun / las mas evidentes cartas / y el número más ceñido / más de dos mil llegaba / prisioneros nueve mil y todas juntas sumadas / diez y seis mil son los /que destrozaron nuestras armas» ${ }^{5}$.

Parecido a los anteriores es el texto de la Relación que al rey miestro Sr haze un Coronel de sus Ejércitos:

«Diose con lauros y triunfos / sin glorioso a la batalla / murieron del enemigo / a los filos de la espada / más de seis mil y ochocientos / cosa, que gran Sr. que espante / quedandose prisioneros / por cuenta justificada / más de ocho mil y seis cientos ${ }^{\circ}$.

En todos ellos hay una voluntad de minimizar y ridiculizar el poderío de los aliados: «Aora, que Galobay / con sus tropas luteranas / en vez de dançar pabanas / todos van diziendo ay / aora, que aqui los tray / nuestro monarca a la vista / para que el sebastianista / confiese lo que negó (...). / Aora, que en la batalla, que allá en Almansa se ha dado. /Todo el despojo ha quedado / de aquella Inglesa canalla»? ${ }^{7}$

Las altas cifras de muertos aportadas por los folletos borbónicos giran entre cinco mil y seis mil ochocientos, y las de prisioneros oscilan entre ocho mil seiscientos y diez mil. Son más bajas que las citadas por Bacallar, que, habla de 18000 hombres perdidos por el rey Carlos sin precisar cuántos murieron y el número de los prisioneros, pero haciéndose eco de una abundante deserción en el ejército austracista. También Bacallar aporta, lo que no hacen los folletos, las muertes entre los componentes del ejército borbónico, refiriéndose a un total de 2500 españoles muertos y más de 1000 heridos. El cronista Belando da cifras parecidas. En el ejército austracista, 6000 muertos y más de

\footnotetext{
3. BC. Folleto Bonsoms, $n^{\prime \prime} 7509$, año 1707.

4. BC. Ave Maria... Folleto Bonsoms, n* 8128, año 1707.

5. BC. Romance de la feliz victoria que logró Felipe Ven Almansa. Folleto Bonsoms, n'7509, año 1707.

6. BC. Folleto Bonsoms, n" 7509 , año 1707.

7. BC. El damzante de Alcorcón que bayla a su son. Folleto Bonsoms, nº 893, año 1707.
} 
7000 rendidos y en el ejército borbónico, unos 3000 muertos. Belando habla tanto de muertos españoles como de franceses, mientras que Bacallar solo habla de los españoles muertos. Las cifras que dan los austracistas como Castellví no varían mucho: 7000 u 8000 mil muertos austracistas aunque incrementa el número de muertos borbónicos (esta vez se habla solo de franceses) a $4000^{8}$.

Todos los textos reiteran la importancia del botín perdido por los aliados. Las cifras de muertos son importantes si tenemos en cuenta que las crónicas atribuyen un montante de hombres en el ejército austracista de unos 20000 hombres y en el borbónico de unos 25000 , lo que significó que del ejército derrotado murió la tercera parte de los participantes en la batalla y del ejército ganador un $12 \%$.

Pero Almansa más que una batalla fue la gran ocasión que necesitaban los borbónicos para difundir sus razones. Éstos, a lo largo de 1705 y 1706, habían sido más sujetos pacientes que agentes de la publicística de esos años. Ahora, en 1707, se producía la inversión en la situación. Los que parecían perdedores se tornaron ganadores e impusieron su argumentación. Almansa fue el hito que permitió cargarse de razones al discurso borbónico.

La publicística analizada de 1707, más que de Almansa hablará de las derivaciones de Almansa. En primer lugar, hay que subrayar las descripciones que se hacen de la proyección posterior del ejército borbónico, y, en particular, su incidencia ulterior en Valencia y Lérida. La Relación puntual de la gloriosa recuperación de Valencia por las armas del rey mandadas por el Duque de Orleans, editada en Sevilla, resalta cómo después de la victoria de Berwick en Almansa, el duque de Orleáns pasó a Requena, Cheste y Buñol, con «poca resistencia». En el campo de Cheste se encontró con los «Diputados de Valencia» que se «rindieron el 8 de mayo de 1707», seguidos de los miquelets y los «rebeldes» que se refugiaron en Morviedro y después pasaron a Tortosa «abandonando sus familias y haciendas por su rebeldía y malas operaciones»".

Los folletos pasan como sobre ascuas sobre la represión borbónica en Valencia, cosa que, en cambio, los cronistas borbónicos, más tarde, tratarán, sin mayores complejos, reconociendo que la victoria borbónica de Almansa estimuló la resistencia de las poblaciones valencianas (Alcoi, Xàtiva, Alzira, Dènia...). Un borbónico como López de Mendoza responsabiliza directamente a Felipe V, a su entorno cortesano y a las tropas francesas de Asfeld de todo lo sucedido en Xàtiva: «Se aprobó en la corte de donde salió decreto»y «se convirtió en una sangrienta tragedia, no quedando nada vivo». Bacallar escribe: «Ellos y los vencedores aplicaban fuego a las casas: aquellos por desesperación cruel y éstos por ira (...) nada quedó en Xàtiva, ni aún el nombre», nombre que como sabemos el rey Borbón cambió por el de San Felipe. Belando es tam-

8. V. BACALLAR (marqués de San Felipe). Comentarios de la guerra de España e historia del rey Felipe V. el animoso. Edición e introducción de C. Seco. Madrid, 1957, p. 131; N. BELANDo. Historia civil de España. Sucessos de la guerra y tratados de paz, desde 1700 a 1733. vol I, ps. 310-311; F. de Castellví. Narraciones históricas. Edición de J. M. MUNDET y J. M. ALSINA. Madrid, 1997, vol H, p. 355.

9. BC. Folleto Bonsoms, $\mathrm{n}^{\circ}$ 3002, año 1707. 
bién muy beligerante contra la carnicería cometida por los franceses en Valencia: «Se cometieron tantas tiranías, extorsiones e injusticias que se pudiera llenar un libro» ${ }^{10}$.

Desde Almansa, la publicística borbónica se va a lanzar sobre todo a robustecer su discurso ideológico frente al austracismo. Sobre todo, intenta revalorizar la figura de Felipe V derrotado en el sitio de Barcelona en abril de 1706. Los borbónicos son conscientes de las críticas que recibían de los austracistas e incluso, de algunos de su propio bando, después de la llegada de la armada inglesa, capitaneada por Peterborough, a principos de mayo, en la capital del Principado catalán y la consiguiente huída del de Anjou a Francia en 1706 en lugar de volver a Madrid" .

La publicística borbónica de 1707 intenta, estratégicamente, desmentir la «traición» de Felipe V en 1706 y, además, en la Carta y compendio historial de los sucesos de España y sus dominios se justifica la actitud penalizadora de Felipe V con el argumento de que éstos se rebelaron contra él ya desde 1704 «llamando a los enemigos que con su armada grande se acercaron a Barcelona)y. Añade que, de nuevo, en 1705, la erosión sufrida por los borbónicos fue importante tras las reiteradas demandas de ayuda de los catalanes a la armada aliada: «Se sublevó todo aquél país, contra él, haziendose dueños de todas las Plazas menos de Barcelona, que por estar bien guarnecida y fortificada se resistió desde primeros de agosto hasta parte de octubre que se rindió no a la fuerza de los sitiadores, que eran pocos mas que los sitiados, sino al golpe de todo un País y consternación de los ciudadanos que se habían estado a la mira para ocultar su veneno, hasta que con lo adelantado de la estación, temieron que no pudiendo subsistir la Armada, se aventurase la empresa» ${ }^{12}$.

10. A. LÓPEZ DE MENDOZA (conde de Robres). Historia de las guerras civiles. Zaragoza, 1882, p. 343; V. BACALlAR. Comentarios... p. 312; N. BELANDo. $H^{a}$ Civil... p. 322; E. Giménez. Militares en Valencia (1707-1708), Alicante, 1990, ps.9-49; R. Ma ALABRUS (Ed.). Escrits politics del segle XVIII. Tom IV. Cròniques de la Guerra de Successió. Estudi introductori, Vic, 2006, ps. 43-44.

11. V. BaCAllar. Comentarios... p. 103; N. Belando. $H^{u}$ Civil... ps. 270-273 y 282-287; A. López dE MendozA. Historia...ps. 294-295; R. Ma Alabrús (Ed.) Cròniques... ps. 19-28. A lo largo del siglo XVIII la «fuga» borbónica siguió acaparando protagonismo. Incluso en fechas tan tardías como la de 1773 la crónica borbónica del Genio de los Naturales de Cataluña (BC, Manuscrito n 119 ) insistía en justificar el tema, para contrarrestar los panfletos evocadores de la memoria histórica austracista, contra Carlos III, que se difundieron en el barrio del Born de Barcelona, a raiz del motín que provocó el reclutamiento de las quintas, además del contexto revisionista de la Nueva Planta para la Corona de Aragón propiciado por las expectativas generadas por el conde Aranda entre los catalanes; LL. ROURA (Ed.) Precauciones contra alborotos, motines y rebeliones en la plaza de Barcelona. Pedro de Lucuce. Estudio introductorio, Vic, 2002.

12. BC. Folleto Bonsoms, $\mathrm{n}^{\circ}$ 2995, año 1707; AHMB (Archivo Histórico Municipal de Barcelona). Manuscrito B-152, año 1772. La huída de Felipe V fue contrarrestada, además, por los borbónicos con la negación de la adhesión de Barcelona, en 1705, al archiduque Carlos. Ello levantó ampollas entre los austracistas catalanes que imprimieron textos, a lo largo de 1707, como el de la Veridica Relación diaria de lo sucedido en el ataque y defensa de Barcelona y en el Principado de Cataluña en 1705 donde se desmentían tales hechos. De este texto he encontrado tan solo una copia de 1772; J. MORALES ARrizaBAlaGA. La derogación de los fueros de Aragón (1707-1711), Huesca, 1986. ps 38-39. El autor expone los argumentos borbónicos que llevaron a Felipe $\mathrm{V}$ a reprimir y confiscar los bienes de la Corona de Aragón. 
En Ave Maria. Extollens vocem quaedam se pretende justificar no solo la partida del rey en 1706, sino la anterior de 1702 que ya había suscitado todo tipo de habladurías entre los borbónicos y críticas de los austracistas: «Desde que fue a Nápoles sufrió conjuras de su vasallos» y «unos le persiguieron por costumbre, otros por malicia, otros por ignorancia, y hubo de sufrir conjuraciones hasta de sus más obligados vasallos» ${ }^{13}$.

El refuerzo de la imagen de Felipe $V$ también va acompañado de una estrategia de descalificación obsesiva de los catalanes como instigadores de las rebeliones de toda la Corona de Aragón desde 1704 y así legitimar la guerra abierta contra ellos. Ello se manifiesta en la Carta y compendio historial de los sucesos de España... publicada ese mismo año en Sevilla: «Empezóse a abrir esta brecha por los Catalanes como más peritos en sublevaciones y llamando a los enemigos que con su armada grande se acercaron desde 1704» y «aplicaron toda la fuerza de su industria para defender sus fueros» ${ }^{14}$.

Estas acusaciones conllevan un tono muy altivo y amenazador también contra todos los ciudadanos de la Corona de Aragón: valencianos, aragoneses y especialmente catalanes. En El danzante de Alarcón que bayla a su son se alaban las proezas del general Berwick en Almansa y al mismo tiempo se esgrime:

«Aora que el valenciano / reconociendo su error / al oir otro tambor / dexa el que toca el villano. / Aora que al casquibano / de Basset, por sus locuras / le dan en las mataduras / por lo que antes hurtó (...). / Aora sí, que ya Berwick / valeroso campeón / nos haze alegrito el son / y va caminando a Vich (...). / Aora sí, que baylaré yo. / Aora sí, que denantes no. / Aora, que Zaragoza / y lo interior de su buque / reniegan del Archiduque (...). / Aora, que ya no goza / del sosiego que tenía / porque con su fantasía / ella misma se cegó. / Aora, que a Cataluña / le van dando fuerte guerra / tres ejércitos por tierra / hincándole bien la uña. / Aora, que aunque lo gruña / le han de hazer que lleve / el son de D. Felipe de Borbón y dejar el que tomós ${ }^{15}$.

También en El cardador de Segovia da el parabien a la reina de España nuestra Señora por haberse logrado en aquella ciudad de esperanza de la sucesión deseada de estos reinos... y por la victoria y triunfos del Señor Felipe $V$ se advierte a Aragón:

"Que el esfuerzo de Berwick / ha rendido porque sirva / de exemplar a los rebeldes / que contra el rey se conspiran / de Valencia, de Aragón / los lamentos nos lo digan / pues aun duran sus suspiros que / su aliento desaniman» ${ }^{16}$.

Para fortalecer estos argumentos se critica sistemáticamente al Archiduque Carlos y se acusa a los austracistas de herejes, si bien lo último se agrandaría mucho más a partir de 1709 cuando el Papa Clemente XI rompió con Felipe V y apoyó abiertamente la candidatura de Carlos al trono de España. En la canción real El monarca perseguido por un principe ambicioso se dice:

13. BC. Folleto Bonsoms, $n^{\circ} 8128$, año 1707.

14. BC. Folleto Bonsoms, $\mathrm{n}^{\circ}$ 2995, año 1707; R. GARCÍA CÁrCEL. Felipe Vy los españoles, Barcelona, 2002, ps. 99-106.

15. BC. Folleto Bonsoms, $n^{\circ} 893$, año 1707.

16. BC. Folleto Bonsoms, $\mathrm{n}^{\circ} 891$, año 1707. 
«Triunfa Felipe y tanto / que la punta sangrienta de tu espada /a la victoria de tan digna entrada / que sea de Almansa fiero espanto / banderas, pavellón, riqueza y quanto / de su Liga temido / ponga el miedo en olvido / por trofeo inmortal de la edad nuestra: / logra lauros tu exercito y tu diestra / atónito el contrario, mudo y yerto / en fuga alienta el brío sino muerto / y sepa el orbe que en tanto arduo empeño / eres de España rey y nuestro dueño / suspende Apolo el bélico instrumento / que si me encumbro, más no seré oydo / y en pielago de afecto sumergido / temo falte la voz, falte el aliento $\rangle^{17}$.

En el caso del mencionado Cardador de Segovia... se habla de:

«El sol de España Felipe / vuestro esposo y nuestra vida / rompiendo los horizontes / sus ardientes rayos vibra (...). / Pues viniendo victorioso / de los que a España oprimian / estos triunfos en tu altar/con fineza sacrifica (...) / manifestando victorias / contra el Inglés calvinista / contra Lutero, contra Arrio / y contra la Apostasía (...) $>{ }^{18}$.

Pero también conviene resaltar que no todo el discurso de la publicística borbónica es unívoco. No todos los borbónicos veían con buenos ojos el regalismo y el aumento fiscal (mantenido por el sector Orry, Orsini, Macanaz) acrecentados por las necesidades de la guerra. El danzante de Alcorcón que bayla a su son se jacta de que Valencia, por fín, quede sometida a un régimen fiscal como en Castilla, lo que sus fueros hasta ahora impedían: «Aora, que ya enValencia / sin atender a los Fueros / les ponen unos Gayteros / ajustados de conciencia. / Aora, que a competencia/ pagaran sin cortapisa / millon, alcabala y sisa como Castilla paga $>{ }^{19}$. En cambio, en la Respuesta y glosa a una representación, que el marqués de Mançera hizo al Duque de Anjou se evidencia como los grandes de España no estaban dispuestos a pasar por la penitencia del aumento fiscal, negándose rotundamente a las pretendidas reformas del presidente del Consejo de Castilla Francisco Ronquillo:

«Y digan todos los Grandes (...) verse mandados por el silvo de los franceses, despojados de sus rentas (...) es verse oy Ronquillo infame mandadero de las insolencias francesas, sino conocer que dorándose tan amarga píldora con el oro falso de aparentes horrores, le hazen universalmente aborrecido a los españoles, como generalmente dominado, aún más del indigno francés (...). Hazer pecheros tus antiquissimos mayorazgos? Sujetar tus lugares y haziendas al favor de la guerra, porque un vil galopin frances te permita entrar a hazer bulto en la antecámara de Horri?».

El texto borbónico no tiene ningún reparo en seguix criticando a los arbitristas franceses que rodeaban a Felipe V y a María Luisa:

«Con su pretexto se amontonaron las contribuciones, se violentan los paisanos y se saquean los pueblos con transitos y alojamientos de tropas. Y lo que es mas, en estas mismas se introducen los dogmas de Calvino, que vomitados de la Francia, hazen justo a los antes religiosos ojos castellanos el despojo de los templos, la profanación de los altares y el pisar al mas soberano sacramento» por lo que pide al Duque de Anjou que reflexione y los aparte de su lado:»Y por último llora el de Anjou. O que llanto (...). No sois el que

17. BC. Folleto Bonsoms, $n^{\circ} 3111$, año 1707.

18. BC. Folleto Bonsoms, $n^{\circ} 891$, año 1707.

19. BC. Folleto Bonsoms, $n^{\circ} 893$, año 1707. 
dio leyes a los españoles? El que borró fueros, atropelló noblezas, empobreció los erarios de caudales, y los pueblos de vidas? No tenéis contenido a vuestro abuelo? Pues porque Ilorais? (...) Es ser rey de España, hazer un Decreto y llegando a manos de Horri, romperle y arrojarle Horri y tirar los fragmentos a la cara de quien se le llevó, diziendo, no quiero, porque el rey no sabe lo que se manda? Es ser rey de España, no tenr dominio, ni libertad para castigar los delitos? Y sino dezidme, Duque, que francés os habéis atrevido a castigar, siendo inumerables las insolencias que esta nación ha cometido en los que llamais dominios vuestros? Es ser rey de España disipar los erarios españoles, para hartar a la codicia francesa? Es ser rey de España sujetar vuestras menores resoluciones a los vergonzosos dictamenes de Damelot y la de Ursinos? Es ser rey de España, respirar millones de tiranías, complaciendoos, y sufriendo, que las carceles y calaboços de Francia, opriman a la primera nobleza española, sin reservar aquella real persona que adoró el mundo? $\gg^{20}$.

\section{EL DISCURSO AUSTRACISTA}

La publicística austracista silenció Almansa. Feliu de la Penya, muy discretamente, en sus Anales de Cataluña atribuyó la derrota austracista a la inferioridad numérica del ejército austracista sobre el borbónico, y, desde luego, a la impericia de los generales Galway y de Las Minas. Liechtenstein en sus cartas al rey-archiduque Carlos insinuó traición y negligencia. En su momento, se comentaron mucho las inhibiciones sospechosas del marqués de Las Minas. Galway, por su parte, le echó las culpas al propio Carlos por sacar del frente algunos batallones y trasladarlos a Cataluña para reforzar el ejército allí. Peterborough defendió, por su parte, a Carlos. El debate sobre responsabilidades entre el bando aliado fue acre en los altos niveles de la política, pero no se reflejó en la publicística ${ }^{21}$.

El rey Carlos III tomó medidas, desde Barcelona, para resguardar al Principado de la ofensiva borbónica, después de Almansa. La caída del reino de Valencia y la posterior toma de Lérida le apresuró a establecer, a finales de diciembre de 1707, un decreto firmado por el secretario de Despacho Ramón Vilana Perlas por el que se pretendía la configuración de un ejército preferentemente de soldados catalanes, ya que la ayuda de la armada aliada no llegaría a Barcelona hasta el verano de 1708 con Elisabet Cristina. Las condiciones del rey y de Vilana para la obtención de los soldados fueron muy concretas:

«En la del Regimiento de mi Real Guardia Catalana, compuesto de 600 hombres, en donde todos los oficiales mayores y menores seran de la misma Nación, excepto el Coronel, en el caso de que sea mi voluntad conferir este empleo a uno de mis Generales: en un regimiento de artilleros de 400 hombres, que se formará en este Principado, del qual se necesita para asegurar la más vigorosa defensa de las Plazas y Presidios, que le guarda: en 1500 de montaña, que los Cabos sean siempre Catalanes: y en los dos regimientos de Cavallería de Don Rafael Nebot y Don Felipe Sobias, compuestos juntos de 1000 hombres, cuyos oficiales, por la mayor parte, son Catalanes, deviéndose creer, que mi justificación

20. BC. Folleto Bonsoms, $n^{\circ} 3095$, año 1707.

21. N. Feliu de LA PENYA. Anales de Cataliña, Barcelona, 1709, vol. 111, p. 592; P. Voltes, Barcelona durante el gobierno del Archiduque Carlos de Austria, Barcelona, 1963, vol. II, ps. 134-141. 
atenderá a los méritos de los nacionales de Cataluña, anteponiéndolos a otros, en quienes concurran iguales en las vacantes de los empleos de los dos últimos regimientos de Cavallería y del de Artillería» ${ }^{22}$.

Almansa comportaría la supresión de los fueros valencianos y aragoneses y, desde luego, un importante flujo de exiliados de ambos reinos hacia Cataluña. V. Gascon Pelegrí cita un total de unos 95 eclesiásticos y 172 seglares recién llegados al Principado a finales de 1707 . V. Graullera aporta una lista aproximada de unos 307 residentes de origen valenciano en Barcelona a partir de 1707, algunos nobles como el marqués de Boil y sus hijos, el marqués de Carroz, el barón de Llosa, el marqués de Costa o los marqueses de la Vega entre otros, así como cargos de la administración real e incluso algunos oidores de la Audiencia, hasta clérigos, ciudadanos y juristas ${ }^{23}$.

El rey Carlos fue paternalista con todos ellos y les otorgó diversas mercedes y concesiones nobiliarias, a fin de mantener su confianza, prebendas que se incrementaron cuando la boda real con Elisabet Cristina en 1708. Algunos de los afortunados fueron los aragoneses: Pere Villacampa, Esteve Mir, Josep García y Tolba, Francesc Ibàñez de Aoyz o los valencianos: Onofre Izquierdo, Josep Vicent Tomàs Eiximeno, Tomás Cabanilles, Simó Carros y Vilaragut, Josep Belbís, Pere de Valterra y Blanes, Ramon de Belloch, Jaume Rosell, Josep Micó... que habían tenido cargos en la administración austracista en Valencia y Aragón ${ }^{24}$.

En Cataluña, después del fracaso de Felipe $\mathrm{V}$ ante Barcelona en la primavera de 1706 había habido una importante represión contra todos aquellos sospechosos de ser afectos al Borbón. Algunas penas de muerte y el secuestro de los bienes de al menos sesenta familias de la nobleza (los Cardona, Montalto, Ixar, Béjar, Tamarit, Torralba, Plasencia, Aitona, Peralada, Darnius, Robles, Erill, Alba, Cerdanyola, Albam, Camarasa, Rosa...) y de otros militantes (Los Agulló, Rocabertí, Josa, Pastor, Cortada, Portell, Potau, Orús, Rull, Comes, Martí, Ametller, Güell, Prou, Pallejà, Copons, Puiggener, Calvo, Ximénez, Margarit, Tamarit, Caramany, Vilaferniu, Escofet, Viladench...). A algunos de ellos, Felipe los insertó en cargos de la administración castellana, aunque otros se exiliaron al sur de Francia.

La derrota de Almansa radicalizó esta represión en Barcelona. En enero de 1707 se habían confiscado los bienes de la familia Alós. En mayo se había condenado a muerte a Feliu Martorell de Constantí. Después de Almansa se elaboró una nueva lista de confiscaciones de bienes a la que se añadieron las familias Matas, Bru, Compte, Faust, Cargol, Gelabert, Recasens, Mouràs... En 1708 se registró una nueva lista de 187 personas, «botiflers» de menor peso, a los que se les embargaron sus propiedades (los Sentís, Cortiella, Parera, Monrrós, Reverter...) y otra lista paralela de borbónicos procedentes de diferentes lugares de Cataluña (Ferran, Abat, Pedrals...). También en 1708

22. BC. Folleto Bonsoms, $n^{\circ} 4095$, año 1707.

23. V. GASCón PELEGRí. La región valenciana en la Guerra de Sucesión. Valencia, 1964; V. GRAULlERA. Los notarios de Valencia y la Guerra de Sucesión, Valencia, 1987.

24. N. Feluu. Anales... op. Cit., vol. III, ps. 598-615; P. VÖLTES. Bäceloná durante... op. Cit., vol. Iİ, p. 187. 
se condenaron a muerte a Jaume Cortiella y Pere Bressiani y al año siguiente Francesc Pons, Salvador Solà y Nicolau Romello, a la vez que siguieron las confiscaciones de bienes (a los Cartiella, a Francesc de Erill -marqués de Rupit-) ${ }^{25}$. La publicística austracista no menciona esta represión sino que, al contrario, incide en la violencia llevada a cabo por los borbónicos después de Almansa en Valencia. El folleto Las Agonías de la Francia y religiosos austriacos ardimientos para la defensa de Nuestra Fe Católica denunciaba el vandalismo cometido por los franceses en las iglesias, después de la pérdida de Almansa y la caída de Valencia, así como las confiscaciones llevadas a cabo por el equipo de Orry:

«Sirviendo también aviso / y de doctrina importante / esta divertida a obstinados / que sus agravios aplauden. / Oygan, pues, que la sugeto / de la prudencia al examen / pues mi católico zelo / solo publica verdades / y al ver desechas las tramas / que con Francia nos esparce / siendo en todo, esta nación / de sus mentiras, la madre / y ensalça la casa de Austria porque es muro inexpugnable / de su fe, contra las furias / de la Francia, y sequaces (...) de la católica fe, y el defensor más loable / de la sacra religión / el que para compararle (...) de inocentes sacerdotes / que al sacrilego corage / de franceses fueron muertos / en la iglesia, a centenares! $)^{26}$.

Paralelamente el discurso austracista intentó minimizar la victoria de Almansa sobre la base de recordar las derrotas francesas previas. Ello se puso de manifiesto exaltando las heroicidades de los catalanes, a lo largo de la historia, contra los franceses. Así en el folleto Leales y amantes expresiones de un Celeste Establecimiento del Principado de Cataluña (...) evocaba la defensa contra el sitio realizado en Cataluña por Luís XIV en 1695: «El diez de mayo de 1695 en este mismo Principado en el llano den Baz, unas pocas esquadras unicamente de miqueletes cathalanes, comandadas por héroes inmortales, Ramón Sala, veguer de Vique y D. Joseph Mas de Roda, travaron tal batalla (...) que por las rabiosas balas que escupían sus pistolas y escopetas catalanas quedaron muertos 200 enemigos quedando mal heridos unos 500 y arrojando el resto de un total de $900 »$. El texto hace también una especial alusión al sitio de Barcelona por Felipe $V$ en 1706, con una voluntad de transmitir coraje y un estado de alerta a los catalanes, que si en ese año vencieron a Felipe $\mathrm{V}$ y le frenaran el paso, ahora, después de lo sucedido en Almansa piensan: «Está Felipe dentro de Cataluña, con muy poderosos ejércitos, y que Barcelona se le rinda, sino es cierto, es por lo menos posible y en vistas de esto, no quedarse los pueblos a la mira de lo que puede ser; no estarse en sus casas quietos, para así sacar algun buen partido de la indignación de Felipe en caso que logre sus designios! Sino que tomando las armas, todos por Carlos han de aventurarse, teniéndose con Felipe por malganados y con Carlos por bien perdidos» ${ }^{27}$.

25. J. ALBAREDA. El «cas dels catalans». La conducta dels aliats arran de la Guerra de Successió (17051742), Barcelona, 2005, p. 61; P. VolTES. Barcelona durante... op. Cit., vol. II, ps 152 y vol. III, ps. 95-102.

26. BC. Folleto Bonsoms, $n^{\circ} 3076$, año 1707 .

27. BC. Folleto Bonsoms, $n^{\circ} 589$, año 1707. 
A través de la evocación de los catalanes ganadores en 1706 se hace una nueva crítica de Francia en El embuste sin verdad y la verdad sin embuste:

«Las astucias francesas / poco han valido / y por más, que soberbias / no han persistido. / Viva, viva Inglaterra / y Olanda asimismo / pues por mar y por tierra / en todo asisten (...) que se vuelva en Francia / Borbón Felipe / porque ya en España / no valdran piques (...). / Viva Cataluña / pues mereciste / ser dichosa en primera / en darte a tu príncipe / Viva Carlos Tercero, viva. / Viva Austria. / Viva Carlos Tercero, viva / y viva, viva Barcelonas) ${ }^{28}$.

En cambio se ridiculiza sistemáticamente el descalabro de Felipe $V$ y su marcha a Francia:

«En fin abandonando el señor duque la empresa, y dejando en el campo con el número de cinco o seis mil muertos, los ricos despojos de montes de trigo y cevada, con infinidad de artillería, y todo género de pertrechos de guerra; y lo que es más, sepultada la reputación de sus armas precipitada marcha con la triste luz, que le permitía el fatal eclipse para refugiarse en el Rosellón en Francia, por el consejo del mariscal Tessé, no advirtiendo que si salvare la mayor parte de las tropas de Francia, perdía toda la honra de Europa, donde el abandonar en este trance la monarquía de España, se había de mirar, como infeliz pronóstico del derrotado duque, y felicísimo para las justificadas armas de Carlos III triunfante ${ }^{29}$.

En esta misma línea y de una forma más jocosa, en la Bonaventura d'una gitana al Duc d'Anjou, hay una especial delectación en la memoria de los desgarros franceses previos:

«Diguè una gitana / al net de Lluís / la bona ventura / exint de París / y li dona avís / segon ohiras /adeu duch de Anjou / fins que tornaras (...)./ Per fas, ó per nefas / te veus elegit / Rey de las Españas / de molts no aplaudit / miro que aturdit / ho abandonaras / adeu duc de Anjou / fins que tornaràs (...). / Per mar, y per terra / devant Barcelona / miràs las forças / amb furia nerona / de Eulalia y Madrona / veix te espantaràs / que fugint en França I tot ho dexaràs $\rangle^{30}$.

Se sigue estimulando a la guerra en muchos folletos austracistas del momento:

«Es necesario hacer la guerra a Francia prontamente con todos los esfuerzos; quiero dezir poner todas las fuerzas y no la mitad (...) lo que importa, es, que se debe saber, que cosa la guerra, y los efectos de la guerra; siendo que la guerra es una discordia o disentimiento porque se mueven las armas, por preparar las injurias, o defender la libertad, y así se mueven las armas, es necesario moverlas como han hecho los romanos, que siempre han sido vencedores, quiero decir disponiendo las cosas de tal manera, que se puede vencer, previendo, previniendo y proveyendo $\aleph^{31}$.

La ofensiva contra Francia se convierte en una obsesión: «Deben persuadirse altamente los altos aliados, que en materia de estado los franceses nos seran buenos (...)» y se recrimina a Castilla que les haya dado cobijo: «Si la Noble y generosa Nación Castellana hubiera tenido presente el dicho de este sr. Marte castellano (Gran Capitán

28. BC. Folleto Bonsoms, $n^{\circ} 9579$, año 1707.

29. BC. La Paz Octaviana. Folleto Bonsoms, $n^{\circ}$ 592, año 1707.

30. BC. Folleto Bonsoms, n² 2991, año 1707.

31. BC. El juizio de la Europa. Folleto Bonsoms, n² 2993, año 1707, ps. 124-125. 
D. Gonzalo Fernández de Córdoba)», ahora, «no quedaría, como queda, expuesta a la insaciable codicia y favor insolente de los franceses $(.).\rangle^{32}$.

Pero la gran jugada de la publicística austracista posterior a Almansa fue la de ahondar en los primeros signos de divergencia en el ámbito borbónico, ya por la cuestión del regalismo, ya por la problemática fiscal. Por lo que respecta al primero, el gran destinatario de las críticas fue Macanaz, personaje enfrentado con la propia Iglesia dentro del bando borbónico por sus posicionamientos regalistas. Macanaz fue nombrado Juez de Confiscaciones en Valencia (1707) donde llevó a cabo un primer intento de desamortización llamando a «todos los eclesiásticos que vivían en Játiva o en sus términos tenían y poseían cualesquiera rentas perpetuas o vitalicias de otros derechos para que dentro de 30 días comparezcan a este Juzgado a justificar fidelidad que haciéndolo se les mandará a sus iglesias o conventos». Obcecado por la infidelidad del clero valenciano (lo creía posicionado a favor de la causa austracista), sugería la penalización de éste. Su regalismo levantó tantas protestas en Valencia que llegó a plantearse su excomunión en 1709 y sin duda influyó en la decisión del Papa Clemente XI de apoyar a Carlos $^{33}$.

Los austracistas estimularon, a lo largo de 1707, abundantes críticas eclesiásticas al regalismo borbónico. En la Mueca de Mojiganga de 1707 se destacan no solo los sacrilegios de los borbónicos en Valencia sino también en Cataluña:

«(...) Y a pesar de la envidia y maliciosa ambición, conocerás en augustos regios obedecida y venerada la Majestad Austríaca, que ha esmaltado los esplendores de su Corona, en fabricar para la defensa de la fe sus vidas, sus vasallos y sus reinos, desempeñando con estas precisas empresas la solidez católica (...) precisada de la propia defensa, para la justísima guerra, ha llamado, la Austríaca Corona, las poderosas armadas inglesas y holandesas y de otras potencias. Y aunque esta razón nos sobran por justísima la universal quietud de Europa con justas y necesarias prevenciones debía armar a todas las potencias contra la Francia; perpetua perturbadora de la Paz común (...) que ultrajando leyes humanas precipitada de su insaciable ambición, no ha dejado Monarca, Reyno, Potencia, ni Provincias, que tirana no haya acometido, perturbado con traiciones, invasiones, exacciones, robos manifiestos, con innumerabilísimos incendios (...) como tratos executados execrables sacrilegios en Flandes, Italia y últimamente en el Principado de Cataluña, como (...) lo

32. BC. La Paz Octaviana. Op. Cit.

33. A. MESTRE. «Religión y cultura en el siglo XVIII» en Historia de la Iglesia en España, Madrid, 1979, vol. IV, ps. 611-617; T. EGIDO. «El regalismo y las relaciones iglesia-estado en el siglo XVIII» en Historia de la Iglesia en España, Madrid, 1979, vol, IV, ps. 127-143; E. GIMÉNEZ. Militares en Valencia..op. Cit. p. 24; T. EGIDO. «El discurso teologizante del anti-regalismo (1709)» en E. SERrano (Ed.). Felipe $V$ y su tiempo. Actas del Congreso Internacional, Zaragoza, 2004, vol. I, ps. 915-932; A. L. CorTÉs. «La Iglesia y el cambio dinástico» en E. Serrano (Ed.). Felipe Vy su tiempo...op. Cit. ps. 991-1012; T. EGIDO. «Los hechos y las actitudes inquisitoriales» en Inquisición en la España borbónica: el declive del Santo Oficio (1700-1808). Historia de la Inquisición en España y América, Madrid, 1984, vol. IV, ps. 1227-1246; C. MARTIN GAITE. Macanaz, otro paciente de la Inquisición, Madrid, 1975; H. KAMEN. «Melchor de Macanaz and the Foundations of Bourbon Power in Spain» en The English Historical Review, vol. 80, n³17, octubre 1965, ps. 699-716. 
gritan en Camprodón, Rosas, Girona, Palamós, La Seu d'urgell, Plana de Vic, Barcelona y su comarca.... $\rangle^{34}$.

Los textos austracistas se hacen eco de la mala influencia francesa en la corte de Madrid propalando los primeros signos del deslizamiento de algunos borbónicos hacia el austracismo (casos de Portocarrero o Folch de Cardona), sobre todo, por cuestiones fiscales. En la obra Teatro de culpa, y pena, en juizio particular de la Monarquía de España dedicado al excelentísimo Señor Monsieur Don Francisco Ronquillo, un austracista castellano ironiza sobre la influencia que los franceses ejercen, en este momento, sobre el presidente del Consejo de Castilla y reprocha a los grandes de España que hubiesen apoyado, inicialmente, la llegada de Felipe $\mathrm{V}$ y su arrepentimiento posterior, después de las medidas fiscales y de la confiscación de bienes tomadas por el equipo de gobierno del Borbón:

«Es menester advertir / que ay tres clases diferentes / ¿Cuáles son? / Son los que estaban / con orden de estuviesen / los ni carne, ni pescado / y luego los felipenses / que son títulos flamantes / que es lo mismo que recientes / ¿Pues porque se les dio el orden? Dióseles, porque al presente / allá no serían más / y para que los Franceses / no tuviesen el motivo / de andar confiscando bienes / Si que títulos de veras / no han de andar en entremeses / pues yo de burlas no soy / que todos mis ascendientes / desde Carlos Quinto acá / fueron Condes y Marqueses / y a Reyes de Austria sirvieron / siempre en las Guerras valientes / por lo que se les honró / y viste en que se le parece / a estos abuelos que dice? / Señor que soy descendiente / Sí, pero descendió tanto / (...) que a usted no lo reconociesen» ${ }^{35}$.

En el pronóstico de las Lletres curioses de la Bonaventura que digue una gitana a Carles III de nuevo se intenta convencer a los grandes de las malas costumbres de gobierno de los franceses, conscientes de los descontentos que habian en Castilla:

«Los Grandes de Espanya / seran malcontents / del govern de França / y de sos consells

/ y sos sentiments / tu els aliviaràs / a deu Archiduch / fins que Rey seràs (...). / Si vols acertaro / pendràs mos consells / desterra de Espanya / tots los malcontents (...) \> ${ }^{36}$.

En El embuste sin verdad y la verdad sin embuste se critica a los que en su momento siguieron las directrices del cardenal Portocarrero, tras la muerte de Carlos II, dando apoyo a la candidatura del duque de Anjou y cuánto pagaron después por ello. El texto establece unos hipotéticos diálogos entre el austracista almirante de Castilla, Enríquez de Cabrera, y el propio cardenal Portocarrero:

«El almirante parece / en esto muy disgustado / y cierto, que su imaginado / verá como desvanece / quisiera yo me dijese / como es estraño Borbón / desta Corona y Tuzon / quando a él no se le oculta / ser de sangre mas conjunta / de quantas al mundo son? / Haga el

34. BC. Folleto Bonsoms, $n^{\circ} 590$, año 1707; J. Ma Torras. La guerra de Successió i els setges de Barcelona (1697-1714), Barcelona, 1999, ps. 194-195.

35. BC. Folleto Bonsoms, $n^{\circ}$ 2999, año 1707; A. MESTRE. Apologia y crítica de España en el siglo XVIII, Madrid, 2003, p. 175; R M AlabRÚS. «El pensamiento político de Macanaz» en Espacio, Tiempo y Forma. UNED-Madrid (en prensa).

36. BC. Folleto Bonsoms, $n^{\circ} 5663$, año 1707. 
lo que quisiera / con todos los de su bando / que este, que intentan quando / no seré como esperan (...) / y cuyden en que su ropa / no se venga a quemar' ${ }^{37}$.

Conscientes del transfuguismo de algunos antiguos borbónicos al austracismo, generado, en buena medida, por los intentos regalistas de Orry y Macanaz en Valencia, los textos austracistas se esfuerzan en subrayar las cualidades y la bondad de Carlos III, poniendo como ejemplo su calidad humana demostrada en 1706 respecto a los borbónicos derrotados: «Ya que por otras muchas ocasiones en que ha demostrado sus misericordias (...) como unas expresamente por haber perdonado a los cavalleros y demás que van siguiendo al de Anjou, con tal, que dentro de cierto señalado plazo vuelvan' y añade:

«Aquel Gran Rey de los Reyes, Nuestro Dios, a aquellos Nobles que dejaron sus domicilios, y no quisieron sujetarse a su Imperio, les consideró de repente por rebeldes, a un eterno destierro, en las mazmorras más sensibles, entre esposas y cadenas las más lamentables. Y su Real Majestad no solamente no les condena por rebeldes de repente, a los que han dejado sus domicilios, si que también les concede ideas de tiempo, para ponerse a la obediencia y suavísimo amparo de su Real Majestad ${ }^{38}$.

También son abundantes las canciones y textos posteriores a la batalla de Almansa exaltando la personalidad liberal de Carlos III, intentando olvidar la derrota y, a su vez, captar a los borbónicos descontentos. Es el caso de los Villancicos que se cantaron en la solemnisima fiesta en la Excelentissima Ciudad de Barcelona con la asistencia de Carlos III o de los Villancicos que se cantaron en la solemnísima fiesta de San Antonio de Padua en el Real Convento del Padre San Francisco de Barcelona ${ }^{39}$. Todos estos villancicos desde finales de 1707 y a lo largo de 1708 acabarán por desvelar los preparativos de la futura boda del rey Carlos III con Elisabet Cristina de Brunswick en Barcelona, donde, sin duda, el autríaco rey de los catalanes, acapararía todo el protagonismo $0^{40}$ sin olvidar que algún día, como en el emblemático y admirado año 1706 , volvería a ser coronado rey de España:

«Seràs liberal / ab gran pietat / donareu al pobre / molta caritat / sa necessitat / la remediaràs /adeu Archiduc / fins que Rey seràs / anireu a Espanya / Carlos molt amat / en la sua Cort / sereu coronat $\rangle^{41}$.

Se insiste en advertir a Castilla de que no debe seguir las recomendaciones del sector arbitrista francés:

37. BC. Folleto Bonsoms, $n^{\circ}$ 9579, año 1707; T. EGIDO. «La oposición al gobierno de Felipe V》 en J. L. PEREIRA (Coord.) Felipe $V$ de Borbón (1701-1746). Actas del Congreso de San Fernando(Cádiz), Córdoba, 2002, ps. 379-400.

38. BC. Leales y amantes expresiones de un celeste establecimiento del Principado de Cataluña y de todo lo demás del reyno de las Españas, bajo el suavísimo dominio de la Cesarea y Real Majestad de Nuestro Rey Carlos III. Folleto Bonsoms. N $^{\circ}$ 589, año 1707.

39. $\mathrm{BC}$. Folletos Bonsoms $\mathrm{n}^{\circ} 9582 \mathrm{y} \mathrm{n}^{\circ} 585$, año 1707.

40. BC. Mercedes que el Rey Nuestro Sr. Carlos III ha sido servido dispensar a sus vasallos el día de su boda. Folleto Bonsoms, $\mathrm{n}^{\circ}$ 9186, año 1707.

41. BC. Lletres curioses de la Bonaventura... Folleto Bonsoms, n 5663, año 1707. 
«Que lástima el ver la nación castellana (...) cuando sirviendo al extranjero poder, que con despotiquez la domina, con arrogancia la humilla ya desprecios la acaba! Y esta infamia, tiene su punto crítico, en el rendirse o no rendirse Barcelona; pues si se rinde se eterniza nuestra esclavitud». Y a su vez se denuncia la vocación imperialista de los franceses que no tardarían en apoderarse de las riquezas españolas en las Indias:

«Les vino el duque aclamado / y no bien pisara el suelo / de Madrid, quando alternaron / sus vitores con lamentos (...) / permiten, que Sevilla / y Cadiz el Gran Comercio / se entregue solo a Franceses / y que solo embarquen ellos (...) / claras señales nos dio / de estas mudanzas el Cielo / en Barcelona y un aviso / nos lo reveló el suceso./ Entró el Rey en Barcelona / defendió de Anjou el cerco / y vengando el Sol su agrario / le oscureció sus intentos $>{ }^{42}$.

Además, la publicística austracista autòctona de 1707 se lanzó decididamente a cultivar el ejercicio de la memoria histórica con la exaltación de personajes muertos por la causa austracista tanto en los sitios de Barcelona de los aliados en 1705 como en el de Felipe $V$ en 1706. Las glosas al príncipe Jorge de Darmstadt, muerto en el sitio de Montjuich de septiembre de 1705 fueron frecuentes. Algunos de los textos publicados son copias de versiones originales de 1705 o 1706. Por ejemplo las Amantes llamas en flamante pyra... de 1707 son una reproducción exacta de la Breve Noticia... de Gavá editada a raíz del asedio borbónico del año anterior ${ }^{43}$. En ambas se resaltan las heroicidades de Darmstadt. En otras ocasiones las exequias o funerales, de personajes estrechamente vinculados al austracismo, conseguían una gran capacidad de convocatoria. Es el caso de los Villancicos que se cantaron en la solemnidad de la profesion y velo negro de la Señora María Rosa Serra y Postius por la Excelentísima Ciudad de Barcelona, hermana del historiador y copista Pere Serra y Postius, mercedario y significado austracista ${ }^{44}$.

En todos estos textos se hace mención, en algún momento, a la corroboración de los afectos de los catalanes y, especialmente, de los barcelones a Carlos III. Uno de los más significativos en este sentido es el de los Afectos barceloneses donde se explicita que la apuesta austracista catalana es irreversible. Al mismo tiempo incita a los diversos grupos sociales sin distinción de género o edad (se dirige tanto a los gremios como a los universitarios, a la Diputación, al Brazo Militar o al clero, tanto a los hombres como a las mujeres o niños...) de Barcelona para que ratifiquen su decisión:

«Ciudad. Barcelona a vuestros pies. / Invicto Monarca está / y en ellos, Señor, os dá: / Nada; pues todo vuestro es. / Diputación. Todos mis hijos os van /recibiendo abierto el pecho, y el amor, a mi me ha hecho / esclava de su galan / Braço Militar. Siempre halla-

42. BC. Verdades y desengaños a los grandes y chicos de los reinos de Castilla. Folleto Bonsoms, $\mathrm{n}^{\circ} 5737$, año 1707.

43. BC. Amantes llamas en flamante pyra erigida el día 14 de diciembre de 1706 para el fineral de Don Jorge Landgrave, principe de Darmstadt. Folleto Bonsoms, $\mathrm{n}^{\circ}$ 567, año 1707; Breve Noticia de la funesta expression se hizo en la Iglesia Parroquial de Gavá para sufragio del alma del Principe de Darmstadt. - Folleto Bonsoms, n 567, año 1706.

44. BC. Folleto Bonsoms, $n^{*} 9584$, año 1707. 
reis la nobleza / con braço armado por vos / firmeza contra firmeza. / Cabildo y Clero. Siguiendo el gran Inocencio / Os expresa nuestro amor / el mas heroyco silencio (...). / Mugeres. De mas, y de otra muger / sabeis ya el dezir y obrar / y lo que es dexan de amar / (ay Carlos!). No puede ser... $)^{45}$. 